\title{
História da Educação Chilena: Um Estudo das Transformações Educacionais de 1970-1973 e seus Reflexos na Revolta dos Pinguins de 2006
}

\section{Education and Student Movements: A study of Educational Transformations in Chile in The Period of 1970-1973 and its Reflections in the Penguins Revolution of 2006}

\author{
Maria Miduri Nodak Wanishi ${ }^{1 *}$, Dayane de Freitas Colombo Rosa ${ }^{1}$, Roseli Gall do Amaral da \\ Silva ${ }^{2}$, José Joaquim Pereira Melo ${ }^{1}$,
}

\begin{abstract}
RESUMO
O presente artigo pretende analisar a história da educação chilena no período de 1970-1973, mais especificamente a proposta de Revolução de Allende (1970-1973) e seus impactos nas reformas educacionais ocorridas no Chile após o golpe militar, assim como sua relação com a Revolta dos Pinguins. As mudanças estruturais - como a reforma agrária e a nacionalização dos bancos, minas e indústrias definiram as transformações sociais no Chile, juntamente com a luta entre a Revolução e a contrarrevolução, na curta era do presidente Allende (1970-1973). Com o golpe militar, as políticas educacionais foram marcadas por reformas neoliberais e a partir de 1990, com a restauração democrática no país, manifestações ocorreram, dentre elas, a "Revolta dos Pinguins", uma mobilização estudantil ocorrida em 2006. A questão norteadora é investigar quais foram as bases que fundamentaram esses movimentos estudantis e qual a sua contribuição para que o Chile se tornasse um país de referência na reforma do Ensino Médio, na América Latina. O que se busca, portanto, é compreender de forma histórica, o movimento dialético e articulado entre a proposta de Allende e a Revolta dos Pinguins e suas contribuições para o processo educacional chileno.
\end{abstract}

Palavras-chave: Educação; Movimento Estudantil; Reformas Educacionais; Ensino Médio.

\begin{abstract}
This article aims to analyze the history of Chilean education in the period 1970-1973, more specifically Allende's proposed Revolution (1970-1973) and its impacts on educational reforms that took place in Chile after the military coup, as well as its relationship with Revolt of the Penguins. Structural changes - such as agrarian reform and the nationalization of banks, mines and industries - defined social transformations in Chile, along with the struggle between Revolution and counter-revolution, in the short era of President Allende (1970-1973). With the military coup, educational policies were marked by neoliberal reforms and from 1990 onwards, with the democratic restoration of the country, demonstrations took place, among them the "Penguins Revolt", a student mobilization that took place in 2006. The guiding question is to investigate what were the bases that supported these student movements and what was their contribution to making Chile a reference country in secondary education reform in Latin America. What is sought, therefore, is to understand in a historical way, the dialectical and articulated movement between Allende's proposal and the Revolta dos Pinguins and their contributions to the Chilean educational process.
\end{abstract}

Keywords: Education; Student Movement; Educational Reforms; High school.

\footnotetext{
${ }^{1}$ UEM-Universidade Estadual de Maringá.

*E-mail: mariamiduri50@gmail.com

${ }^{2}$ UTFPR-Universidade Tecnológica Federal de Apucarana - Pr
} 


\section{INTRODUÇÃO}

Ao refletirmos sobre a América Latina, na maioria das vezes pensamos nos países que se localizam abaixo do Rio Grande, ou seja, abaixo da fronteira entre o México e os Estados Unidos. Dentre os países da América Latina encontra-se o Chile, um país da América do Sul, que pode ser considerado um exemplo a ser enfatizado, pois segundo Lira (2010), apresenta uma das melhores qualificações no Relatório de Desenvolvimento Humano da Organização das Nações Unidas (índice de 0,878) na América Latina.

Esse resultado é fruto de conflitos políticos nos quais os estudantes foram protagonistas, dentre esses conflitos pode-se destacar a Revolta dos Pinguins, para compreendê-lo, faz-se necessário retornar no início da década de 1970, em que o presidente do Chile era Salvador Allende (1908-1973), que venceu em 1970 com 36,6\% dos votos, a eleição para presidente, graças ao apoio dos partidos de esquerda, conhecido como Unidade Popular, no qual pôs em prática o que se denominou "via chilena para o socialismo", que sugeria uma transição gradual e pacífica do Chile para uma sociedade socializante, cujo início foi à reforma agrária e a nacionalização dos bancos e empresas estrangeiras que estavam instaladas no país e consequentemente também das minas de cobre.

Esse projeto proposto pelo então presidente Allende não agradou a classe das elites chilenas, especialmente, as grandes corporações e grupos estrangeiros, que perceberam seus interesses alterados pelo novo governante. Desde então, a gestão do governo de Allende sofreu coação por parte desses grupos. Para Peter Winn (2010), neste momento, "[...] o Chile permaneceu sendo um lugar que o mundo todo observava; não mais por causa de sua revolução pacífica, mas agora por conta de sua violenta contrarrevolução" (WINN, 2010, p.27).

Para o autor, um dos países indiretamente responsáveis por este movimento contrarrevolucionário foi os Estados Unidos, pois estavam receosos pela nomeação de um presidente declaradamente marxista na América do Sul. Além disso, as medidas econômicas de Allende prejudicavam os interesses de empresas norte- americanas no Chile. Segundo Winn (2010):

Embora a elite chilena não necessitasse de lições sobre como defender seus interesses, nos bastidores os Estados Unidos a estavam apoiando por meio de uma guerra velada contra Allende: planejada para bloquear sua revolução democrática, procurava-se desestabilizar a economia do 
país e o governo, preparando o campo para um golpe do Congresso ou dos militares (WINN, 2010, p.27).

A princípio, devido a mobilização do povo, os partidos da Unidade Popular conseguiram conter o movimento contrarrevolucionário, conter greves de empresários e aumentar sua representação no Congresso com a eleição de 1973 (WINN, 2010). No entanto, essa situação política fomentou o apoio das elites econômicas ao Golpe Militar ${ }^{3}$ liderado por Augusto Pinochet (1915-2006) que ocorreu nesse mesmo ano.

No Governo de Pinochet, foi instaurado uma política de repressão social como por exemplo a Operação Condor ${ }^{4}$ e os Chicagos Boys ${ }^{5}$ o que favoreceu para que ocorresse a paralisação da reforma agrária e a nacionalização dos bancos e empresas estrangeiras iniciadas com Allende, bem como a privatização de várias empresas nacionais, dando início ao processo de instituição das ideias neoliberais no país.

No início dos anos 1980, o Chile passou por uma grave crise em virtude de medidas na área cambial com a valorização do real do peso, que associadas a reformas estruturais, juntamente com a política de estabilização, resultaram na pior das crises já encaradas pela população chilena "essa crise agravou ainda mais a desigualdade existente na distribuição de renda" (PEDROSO, 2007, p.95).

Para Mena (2001) esse agravamento da situação distributiva continuou até 1987 quando a renda real per capita e os salários reais eram respectivamente $12 \%$ e $5 \%$ menores que em 1980. O gasto com consumo do governo per capita diminuiu em 30\% e o desemprego atingiu 17\% da força de trabalho nessa década. Entretanto, “[...] anos depois, em uma versão modificada e mais pragmática, as políticas neoliberais levariam o país a uma notável década de alto crescimento econômico com baixa inflação e baixo desemprego, período que viria a ser conhecido como 'milagre chileno' (WINN, 2010, p.28). Ainda segundo Winn (2010), no processo de redemocratização:

\footnotetext{
${ }^{3}$ Para Winn (2010), o Golpe Militar no Chile em 1973 contribuiu para que Fidel Castro considerasse "[...] que a América Latina não estava ainda madura para a revolução e transferiu suas esperanças revolucionárias e a intervenção cubana para a África" (WINN, 2010, p.28).

${ }^{4}$ Segundo Braga (2014) a Operação Condor “[...] nada mais foi que a internacionalização do Terrorismo de Estado no Cone Sul da América Latina” (BRAGA, 2014, p.115).

${ }^{5}$ Segundo Winn (2010, p.143): "Para comandar a economia, Pinochet escalou os chamados Chicago Boys, estudantes com pós graduação na Universidade de Chicago e seguidores das teorias do economista liberal Milton Friedman".
} 
A combinação de economia neoliberal e preocupação social reduziria em mais da metade o legado de pobreza de Pinochet e criaria um 'neoliberalismo com uma face humana', que transformaria o país mais uma vez em um modelo a ser seguido, um modelo de democracia neoliberal cujos líderes iniciaram suas carreiras políticas durante a revolução chilena (WINN, 2010, p.28).

A educação não ficou alheia a esse processo, com Allende pretendeu-se um projeto educacional que se atentou em acabar com a desigualdade social, ampliando o acesso à educação em todos os níveis, ou seja, no primário, secundário e universitário, sugerindo a criação de muitas escolas e incentivando a alfabetização popular. Em 1972 foi apresentado à sociedade o projeto Escola Nacional Unificada, conhecida como ENU, que tinha como objetivo fazer mudanças estruturais intensas na educação, baseada na lógica da unificação do sistema escolar e na centralidade do trabalho para a formação dos filhos da classe trabalhadora, que acabou causando a reação da igreja Católica e dos partidos contrários, que culpavam o governo e a Unidade Popular de fazer da escola um aparelho de manipulação ideológica. Assim, após um ano de discussões, o governo decidiu retirar o projeto de tramitação.

Com o Golpe Militar a educação passou a seguir as tendências neoliberais, realizando algumas mudanças no setor educacional como a municipalização do ensino primário e secundário; uma forte tendência de privatização em todos os níveis educacionais; introdução de vales escolares; a regionalização e financiamento mínimo para as universidades estatais, algumas dessas políticas, como a descentralização, colocaram-se na vanguarda da região, assentando as bases de um programa neoliberal latino-americano (KRAWCZYK, 2009).

O processo de redemocratização trouxe consigo as heranças da ditadura de Pinochet, o que desencadeou o descontentamento dos estudantes e culminou na Revolta dos Pinguins em 2006.

Desse modo, na história da educação chilena destacam-se duas ondas de reformas político-educacionais após o golpe de Estado de 1973, uma de ordem neoliberal, ocorrida no período da ditadura militar (1973-1990), e outra de tipo reformista conservador a partir da restauração democrática nos anos 1990. Os conhecimentos produzidos nessas ondas de políticas se disseminaram de forma amálgama regionalmente, não sendo fácil estabelecer uma diferenciação entre eles.

Foram dessas constatações que se desdobrou a seguinte problematização: Qual a contribuição da proposta educacional de Allende? Em que diferia da educação chilena no 
período de Governo Militar? Quais as influências propostas da reforma educacional de Allende na formação dos movimentos estudantis no Chile? E, quais os possíveis impactos das manifestações estudantis nas transformações do ensino médio chileno, que hoje é referência na América Latina?

Para elucidar estas questões, foi necessário compreender as reformas educacionais chilenas, bem como o processo de transformação social promovido pela materialidade histórica vivenciada por esse país no qual a educação teve papel expressivo.

\section{DELINEAMENTO METODOLÓGICO}

A pesquisa foi de caráter bibliográfico, em fontes constituídas principalmente de livros e artigos de periódicos, como a Revista Cabrochico (1971-1972), que permitiram um suporte histórico relativo ao tema.

Para consecução do objetivo explicitado, os procedimentos da pesquisa incluíram um levantamento documental para posterior análise. O levantamento documental junto ao Observatório de Políticas Educacionais da Universidade do Chile (OPECH) e ao portal MINEDUC, foi realizado no intuito de compreender como a sociedade chilena interpreta os movimentos estudantis ocorridos e quais as mudanças que os mesmos refletiram na educação, pois se entende que a transformação da sociedade, deve-se em parte a essas reivindicações que ocorreram no movimento histórico chileno. No tratamento das fontes, a análise histórica, partiu da hipótese de que “[...] definir as relações humanas como responsáveis pelo processo de transformação coloca o homem na condição de construir sua historicidade e rompe com a concepção de natureza pronta [...]" (PEREIRA MELO; ROSINA, 2007, p.4).

Para Marconi e Lakatos (1999), o pesquisador por meio dos padrões encontrados nos dados para comprovar teorias, hipóteses e modelos preconcebidos desenvolve ideias e juízos, ajustando as possibilidades. Nesta perspectiva, apoia-se com Eric Hobsbawm (1995) em Era dos extremos: o breve século XX 1914-1991, quando explicita que o ofício do historiador contemporâneo é "lembrar o que os outros esquecem" (HOBSBAWM, 1995, p.13), pois segundo o autor, a maioria dos jovens de nossa época crescem como se o presente fosse contínuo "sem qualquer relação orgânica com o passado público da época em que vivem" (HOBSBAWM, 1995, p.13). 
Ao dar início a análise, coube ao pesquisador mostrar-se constante, experiente e instigador, pois os documentos não falam por si só, foi necessário interrogá-los, ou seja, dialogar com as fontes e examiná-las, provando a autenticidade.

Nesse sentido, é importante ressaltar que não se pretendeu fazer uma apologia ao sistema educacional chileno, mas sim investigar neste período histórico como as reformas educacionais ocorridas no Chile contestaram e transformou as necessidades de seu povo. O objetivo aproxima-se dos princípios discutidos por Hobsbawm (1995), sobre o historiador: "compreender e explicar por que as coisas deram no que deram e como elas se relacionam entre si” (HOBSBAWM, 1995, p.13), na busca por entender percepções, as exigências, e direções em relação às revoluções ocorridas no Chile, por meio da transformação educacional por ela promovida e provocar a reflexão acerca de suas consequências.

\section{RESULTADOS E DISCUSSÃO}

Estudar os movimentos estudantis chilenos e seus impactos no processo educacional a fim de compreender as transformações que ocorreram na educação em virtude dessas revoltas populares, é uma temática que necessita ser problematizada de forma histórica, e divulgada, pois não foram encontrados muitos estudos sobre esse assunto, especialmente no que diz respeito à relação entre as propostas de Allende, os movimentos estudantis e a reforma do Ensino Médio no Chile.

Embora Allende tenha governado por poucos anos (1970-1973), seu mandato atraiu a atenção da maioria dos integrantes de esquerda em todo o mundo, pois era composto por uma aliança de esquerda integrada por comunistas, radicais e democratas cristãos, alcunhados de Unidad Popular, que apoiava a passagem gradual do sistema capitalista rumo ao regime socialista em forma de jogo democrático legalizado, tornandose um modelo para os países que desejavam um projeto popular de governo. Para assegurar o novo regime, estava explícito a necessidade de se concretizar politicamente a ênfase em políticas culturais focadas para a preparação de um homem novo, ajustado às modificações deste contexto.

Segundo Zanatta (2017, vários fatores contribuíram para que o Governo de Allende se tornasse um caso de atenção mundial: 
[...] O primeiro e mais evidente foi que pela primeira vez instalou-se pela via eleitoral um governo marxista que expressava sua intenção de construir o socialismo com métodos democráticos. Com isso o Chile se revelou um caso único, diferente de todos aqueles em que o modelo socialista se impusera com uma revolução, como a União Soviética, a China e Cuba. Um caso que colocava a todos, amigos e inimigos, diante de um desafio teórico e prático de enormes dimensões. O segundo fator que tornou esse desafio tão radical foi que o Chile se destacava como um dos raros exemplos de antiga e sólida democracia na América Latina. Portanto, um dos países menos sensíveis às vozes sedutoras do comunismo, cuja capacidade de chegar ao governo de forma legal tinha o efeito de um terremoto. O terceiro motivo é que o sucesso de Allende num país democrático do hemisfério ocidental constituía em si mesmo uma delicada crise da Guerra Fria. A sua vitória num país de regime político em muitos aspectos semelhante ao de alguns países europeus, da Itália in primis, e além disso insígnia da Aliança para o Progresso nos anos de 1960, foi um choque para os Estados Unidos (ZANATTA, 2017, p.195).

Desse modo, Salvador Allende, eleito democraticamente em 1970, foi considerado como o primeiro presidente socialista do continente sul americano, com o projeto único de fazer alterações intensas no sistema social, político e econômico, sem revolução armada por meio do socialismo. Durante os poucos anos que governou o Chile, nacionalizou as minas e quase todos os bancos privados do país, de acordo com Winn (2010), com o auxílio de uma revolução que teve iniciativa dos trabalhadores, dos camponeses e dos moradores das favelas, conseguiu sem agressão a mais rápida e extensa reforma agrária da história chilena.

Segundo Borges (2011), era a chamada "via chilena ao socialismo", que deveria iniciar o processo de transição para o novo sistema apostando na participação popular e no desenvolvimento da economia por meio da nacionalização das áreas econômicas estratégicas, bem como na conquista do poder executivo e legislativo. A inovação desse pensamento de Allende baseava-se especialmente no modelo teórico que negava a violência revolucionária e ajustava a institucionalidade democrática.

Para Santos (2018) o que se destaca nesse aspecto é a inclusão do processo revolucionário dentro de uma tradição nacional republicana, em que os impedimentos ao projeto da UP precisavam ser decididos a partir dos ambientes democráticos, e o trânsito pacífico ao socialismo permaneceria seguido de uma desejada e duradoura paz cívica. Entretanto, essa reforma estrutural apresentada por Allende não foi aceita, causando boicotes por parte de grupos contrários ao sistema socialista.

Sem dúvida, o maior projeto educacional de Allende foi a Escola Nacional Unificada - ENU, que foi demonstrado em 1972 e se baseava na lógica da unificação do 
sistema escolar e na centralidade do trabalho para a formação de filhos da classe trabalhadora, que gerou muitas divergências entre os setores conservadores e da elite chilena, resultando na retirada desse projeto.

Desde o início do governo de Allende, no que se refere ao campo da educação, ocorreu uma abertura ao diálogo entre o Ministério da Educação, o Centro Único de Trabalhadores e o Sindicato Único de Trabajadores de la educación (SUTE). De acordo com Blásquez Figueroa (2019), isso resultou em 1971 no Congresso Nacional de Educação, que estabeleceu direções gerais para se desenvolver um projeto nacional de educação.

Assim, aconteceu o diálogo social aberto e participativo sobre a educação que buscou responder aos assuntos problemáticos que a comunidade decretava como necessidades para a nação chilena. Porém, algumas mudanças no campo da educação não foram possíveis devido à forte oposição por parte de alguns setores da sociedade chilena, como a Escola Nacional Unificada (ENU), que foi a primeira intenção de construir um sistema nacional de educação no Chile vinculado à construção da via chilena ao socialismo.

Outro aspecto a ressaltar na proposta política de Allende foi a tentativa de aproximar a alfabetização à educação popular por intermédio dos meios de comunicação, dentre eles destaca-se a imprensa pedagógica abordada a seguir.

\section{ALLENDE E A EDUCAÇÃO POPULAR: O INVESTIMENTO NA EDUCAÇÃO INFANTIL}

Nesse sentido, cabe ressaltar que dentre os planos do governo de Allende, estava o da relação da educação popular com os meios de comunicação, por meio da conscientização, para isso, tinha como proposta a criação de uma editora pública, que foi inaugurada no dia 12 de fevereiro de 1971, com o nome de Quimantú.

Estes meios de comunicação (rádio, editoras, televisão, imprensa, cinema) são fundamentais para ajudar na formação de uma nova cultura e de um homem novo. Por isso se deverá imprimir neles uma orientação educativa e liberá-los de seu caráter comercial, adotando as medidas para que as organizações sociais disponham desses meios, eliminando deles a presença nefasta dos monopólios (PROGRAMA BÁSICO DE GOBIERNO DE LA UNIDAD POPULAR, 1970, p.31-32). 
Essa nova editora Estatal, com a decisão de publicar livros e revistas alinhadas às expectativas políticas, causou um grande efeito na sociedade do Chile. Estima-se que mais de 12 milhões de livros tenham sido publicados antes do golpe de 1973, sem contar as publicações de revistas de variedades ou revistas em quadrinhos (GOMES, 2021, p.9). Dentre as publicações, encontra-se a revista Cabrochico (1971), apresentada como a principal revista em quadrinhos para crianças na fase pré-escolar, que alcançou a publicação de 70 edições, do seu lançamento em 1971 até o encerramento em 1972, uma revista em que predominava a razão, pela crítica social e demonstração da realidade das crianças chilenas:

Cabrochico, uma revista 'real para as crianças chilenas', nasce para entregar ao público infantil uma escala de valores novos, cujo ambiente seja completamente o do Chile e não o de outros países, com costumes e tensões totalmente diferente dos nossos, como é, por exemplo, aquela que entregam aos seus filhos as publicações infantis que nos chegam diariamente por meio do estrangeiro (CABROCHICO, 1971, p.2).

A revista tinha como temática três blocos que enfatizavam os aspectos didáticos e pedagógicos e um claro compromisso político e secular (GOMES, 2012).

Figura 01 - Primeira Edição da Revista Cabrochico

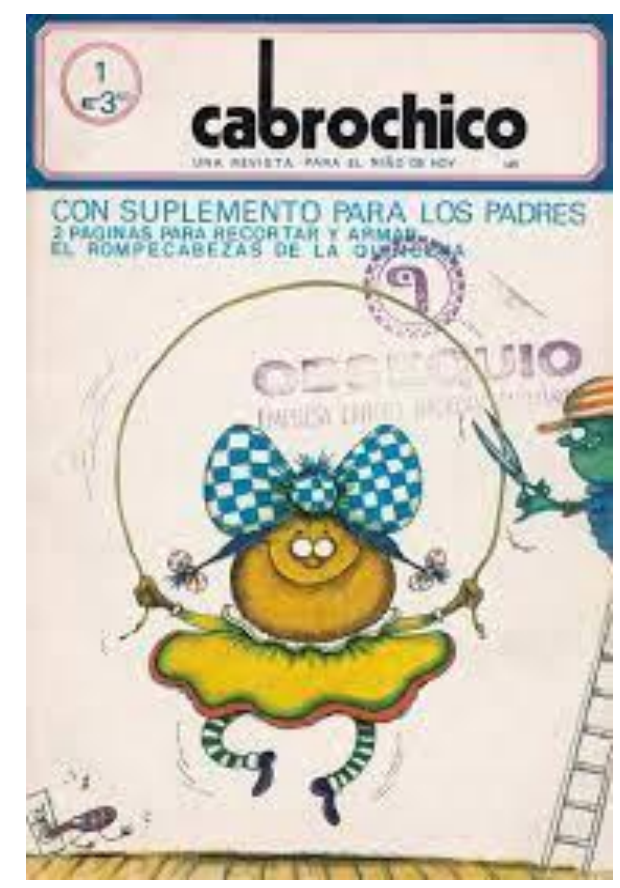

Fonte: CABROCHICO, 1971, capa. 
A revista, editada por Quimantú, Editora Nacional, pretendia romper com a alienação e o processo de influência, considerado negativo, que exercia impacto sobre a formação da consciência das crianças, que sem perceberem, adquiriam a ambição pelo dinheiro, ou se iludiam com um mundo mágico que não existe, como o mundo mágico das fadas e dos duendes. Referiam-se a cultura norte-americana que divulgava alguns dos personagens principais que participam das histórias em quadrinhos que entravam pela fronteira: “[...] o multimilionário Tio Patinhas e a série do Superman, passando por James Bond, até pela fada da Cinderela" (CABROCHICO, 1971, p.2). A revista provocava a fantasia das crianças, cujo desafio era o do esclarecimento das estratégias de alienação do imaginário infantil, procurava demonstrar alguns contos de fadas conhecidos, apresentava as contradições e os limites, para então demonstrar as suas críticas. Nas primeiras páginas da revista explicitava-se o seu objetivo:

Esta nova revista, editada pela Quimantú, Editora Nacional, pretende romper definitivamente com a alienação e o processo de influência negativa que exerce o sistema sobre as mentes infantis que, sem se darem contas, adquirem a ambição pelo dinheiro [...] ou a crença de que existe o mundo mágico das fadas ou dos duendes (CABROCHICO, 1971, p.2).

Nos contos de fadas tradicionais, os personagens principais normalmente são bons, honestos, alegres, simpáticos, trabalhadores, sem ambições, não fazem falcatruas, os verdadeiros heróis infantis. No entanto, Cabrochico (1971) teria a finalidade de demonstrar o "outro lado" desses atores principais, estimulando a criança a perceber e a descobrir sozinha essas contradições. Na abertura da revista, foi abordado o clássico Gato de Botas, história de Charles Perrault, que narra a história de um gato que utiliza diversas estratégias e artimanhas para que o seu amo fique rico e se case com uma princesa, ludibriando a todos que estão a sua volta para conseguir o seu objetivo.

Na história, o rei parece estar o tempo todo desinteressado nas trapaças que o gato pratica, passando muitos camponeses para trás, o que causa uma revolta entre eles, levando-os a se unirem e irem ao palácio do rei, para reclamarem das atitudes do gato. Torna-se explícita a mudança de enredo na revista Cabrochico (1971) quando o amo percebe o que acontece à sua volta, tendo consciência dos atos ilícitos do gato e consegue libertar-se de sua condição de dominado por um animal e mudar totalmente o enredo da história (GOMES, 2012). Como demonstrado na imagem a seguir: 
Figura 02 - El gato con botas.
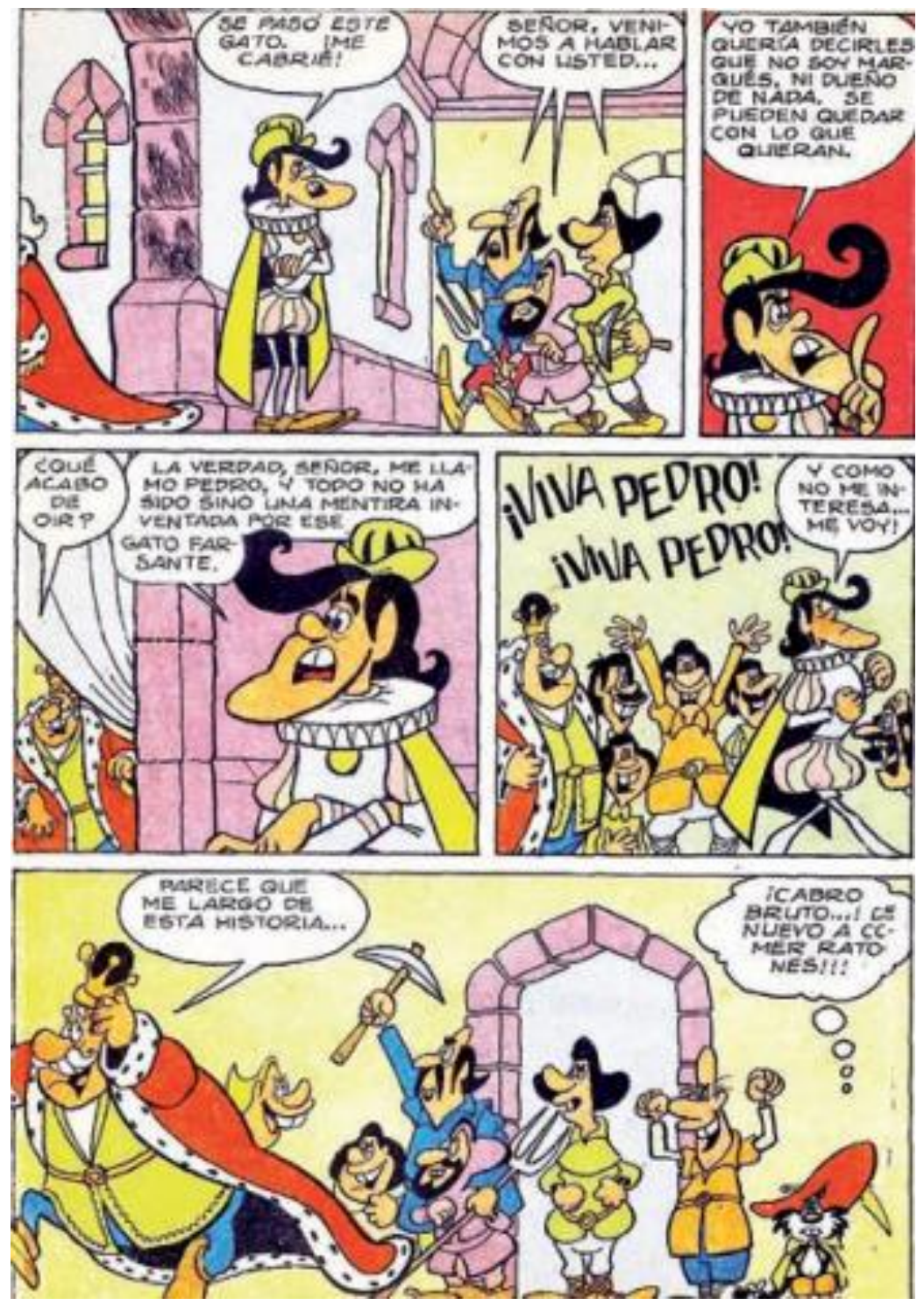

Fonte: CABROCHICO, 1971, p.1-10.

A partir desse ato, o rei sai da apatia e torna-se consciente das maldades do gato, a mudança no enredo da história ultrapassa o egoísmo e a individualidade do gato, prevalecendo a honestidade e a coletividade, demonstrando a inquietação da Editora Quimantú em proporcionar a construção do novo homem, nos limites do governo socialista do Chile. Essas mudanças de comportamentos apontados na revista, nos levam a refletir na contribuição para a formação desses pequenos leitores, levando-os a perceber uma realidade até então desconhecida, transformando-os em adultos não alienados. 
Ao pensar nessas mudanças de comportamentos, em busca do novo homem, o presidente Allende, investiu na educação desde a primeira infância, utilizando as mídias sociais para alcançar os estudantes de todos os níveis e objetivando uma formação desde a mais tenra idade. Fez também inúmeros discursos para os jovens, não somente aos chilenos, mas também aos de outros países quando viajava, um presidente que representava um projeto "novo e jovem" para os chilenos (QUADRAT, 2011, p.1).

Todavia, em 1973 o golpe militar interrompeu as reformas de Allende. O governo militar teve duração de 17 anos (1973-1990) sob o governo de Pinochet, que foi marcado como um período árduo, de perseguição e violência, bem como as políticas econômicas adotadas por esse governo - o que significou as tendências neoliberais do mundo (CABALIN, 2012).

Com essas medidas estabelecidas pelo governo de Pinochet, houve a diminuição dos gastos públicos e com os programas sociais, a privatização do ensino superior e aumento de impostos. Com isso, aconteceu o "milagre econômico" chileno, período de grande crescimento da economia do país, no entanto, provocaram o crescimento da desigualdade social, com o aumento da concentração de riqueza.

Em 1979, segundo Ruiz (2006), o governo decidiu reestruturar o sistema educacional e instalar definitivamente as políticas neoliberais mencionadas. A privatização do sistema educacional, através de um Estado cujo papel "[...] não é outro senão o de entidade meramente reguladora e fiscalizadora" (RUIZ, 2006, p.4) e que implica a consolidação e a abertura definitiva à privatização da educação com recursos públicos, ideia concebida desde o início da ditadura militar.

Após o fim do período militar, o Chile retornou ao governo democrático em 1990, com as reformas estruturais instituídas por Pinochet e as reformas que o governo democrático pretendia realizar. Segundo Higueras (2014, p.30) “duas ondas justapostas de políticas educacionais que o Chile apresentou em 1990”. Desse modo, o governo democrático continuou com a essência do sistema neoliberal, como as políticas de descentralização; com a municipalização de todo sistema fundamental e médio e a privatização; com a transferência de fundo público para o privado, gerando descontentamento por parte dos estudantes. 


\section{A REVOLTA DOS PINGUINS E OS IMPACTOS NA EDUCAÇÃO CHILENA}

Com o golpe militar em 1973, em um contexto de ditadura militar, toda a política pública da educação foi efetuada pelos decretos com força de lei, sem nenhuma discussão, todos firmados pela Junta Militar. Foram nomeados militares de carreira para assumirem as reitorias das Universidades e diretores de Escolas Públicas, ocasionando no controle direto das Forças Armadas sobre as instituições de educação. Iniciou-se um processo de privatização da educação pública, um grande número de estabelecimentos públicos foram cedidos a estabelecimentos privados, criação de escolas particulares que recebiam recursos do Estado.

Ocorreu ainda a descentralização da educação por meio da municipalização, uma política da década de 1980, com a finalidade de que as escolas não fossem dirigidas pelo Ministério da Educação e sim pelas comunas, pelas comunidades. Devido às sociedades em que existem segregação e desigualdades sociais, como a chilena, existem as comunas com muitos recursos e outras pobres, por isso as escolas públicas das comunas mais ricas tinham mais qualidades e as instituições que pertenciam às comunas com menos dinheiro, ficavam em situação de precariedade. Então em todos os níveis de ensino, caracterizouse as desigualdades no sistema de ensino chileno, existiam as escolas e universidades para os setores pobres, para os setores médios e os que pertenciam à elite. Incrementou-se também o acesso ao ensino superior pelo endividamento dos alunos e não pelos direitos sociais, causando revolta e consequentemente os movimentos estudantis.

Em 2006, ocorreu o maior protesto da história chilena depois da ditadura militar, uma passeata de estudantes secundaristas que foram às ruas e ocuparam escolas, que ficou conhecida mundialmente como a "Revolta dos Pinguins", assim chamados por seu uniforme ao estilo do início do século passado. Esse movimento pode ser considerado como uma referência, não somente aos protestos da época, mas principalmente aqueles realizados em diferentes países da América Latina. Para Silva (2017): “os manifestantes adotaram uma estratégia de luta estudantil similar à dos outros países, e, com isso, tornaram-se referência para outros protestos latino-americanos" (SILVA, 2017, p.45-46).

De acordo com Blásquez Figueroa (2019), esses estudantes, a princípio, reivindicavam a gratuidade do exame de ingresso a universidade e também a do transporte escolar, bem como a melhoria da merenda e das instalações sanitárias das escolas. Essas reivindicações iniciais dos estudantes foram atendidas rapidamente pelo governo de 
Michelle Bachelet, no entanto, esse movimento foi ganhando adesão das famílias e outros setores da sociedade civil, como o sindicato docente, que concedeu amplitude ao movimento dos estudantes e passaram a incluir as reivindicações iniciais, a anulação da Lei Orgânica Constitucional de Ensino (LOCE) e a alteração ou anulação da Jornada Escolar Completa (JEC). Dessa forma, ao passo que as reivindicações se tornaram maiores foi necessário criar um Conselho Assessor Presidencial para discuti-las e colocálas em votação o que mobilizou o governo recém-empossado de Michelle Bachelet, levando à realização de reuniões ministeriais de emergência, pronunciamentos do Legislativo, dos empresários, manifestações do sindicato docente (denominado Colégio de Professores), das universidades e de outras entidades. E, a subsequente demissão do ministro de Educação foi um fato traumático para as esferas oficiais, com grande repercussão nos meios de comunicação e na área política (ZIBAS, 2008).

As novas reivindicações levaram também a presidenta a elaborar um novo projeto de lei que pudesse substituir a LOCE. Sobre essa proposta que ficou conhecida como Lei Geral de Educação (LGE), Zibas (2008) argumentou:

Os partidos de oposição, comumente chamados 'de direita', reunidos no bloco denominado Alianza, acusaram o projeto oficial de não assegurar a liberdade de ensino nem resolver os problemas de qualidade, além de ideologizar a educação. Economistas apontaram que a proposta desqualificava a iniciativa privada. Alguns dos liceus municipais, denominados 'paradigmáticos' ou de excelência, com sólida reputação de qualidade baseada em rigorosa seleção de alunos, passaram a discutir as vantagens e desvantagens de seu tradicional processo seletivo. Finalmente, a Igreja católica, grande beneficiária do financiamento público da escola privada, levantou forte crítica ao projeto [...] (ZIBAS, 2008, p. 204).

O projeto de lei não foi aprovado mesmo com a tentativa de nova manifestação dos estudantes em 2007 que foi rapidamente reprimida. Entretanto, a oposição propôs um projeto alternativo que ao perceber a impossibilidade de aprovação elaborou uma proposta de acordo que foi assinada, o que modificou de forma significativa o que foi proposto pelo projeto de lei da presidenta Michelle Bachelet. Nesse acordo ficou estabelecido, segundo Zibas (2008, p.204), algumas mudanças no sistema educacional: “[...] o ensino fundamental (enseñanza básica) foi reduzido de oito para seis anos. O ensino médio foi ampliado de quatro para também seis anos, sendo que as duas últimas séries desse nível deveriam se transformar em cursos de especialização, compreendendo três ramos: científico, humanístico e técnico-profissional”. Mediante a esse contexto a 
Constituição Federal Chilena de 2010 passou a garantir em seu Capítulo III que trata sobre Os Direitos e Deveres Constitucionais no Artigo 19:

Os pais têm o direito preferencial e o dever de educar seus filhos. Corresponderá ao Estado outorgar especial proteção ao exercício deste direito. Para o Estado é obrigatório promover a educação de jardim de infância e garantir o acesso gratuito e o financiamento fiscal ao segundo nível de transição, sem que este constitua requisito para o ingresso na educação básica. A educação básica e a educação média são obrigatórias, devendo o Estado financiar um sistema gratuito para tal propósito, destinado a assegurar o acesso de toda a população. No caso da educação média este sistema, em conformidade com a lei, se estenderá até cumprir os 21 anos de idade (CHILE, 2010, tradução nossa $)^{6}$.

Desse modo, cabe ressaltar que atualmente o Ensino Médio chileno de duração de 4 anos é considerado como um modelo para América Latina, e a Reforma do Ensino Médio chilena pode ser entendida como um fruto dessas revoltas, pois de acordo com Leal (2008, p.38) do ponto de vista teórico "as revoluções, por históricas, são fundamentalmente fonte de lições", desse modo, faz-se importante historicizar as relações sociais desenvolvidas no Chile e os processos educativos desencadeados a partir do processo de transformação social por ela promovido.

Segundo Zibas (2008) o acordo assinado ocultou várias reivindicações do movimento dos pinguins, como por exemplo: “[...] a revisão da JEC, o fim do lucro em educação, o estabelecimento de menor número de alunos por classe e a extensão do currículo para incluir formação sindical e educação sexual”' (ZIBAS, 2008, p.205), o que levou a autora problematizar se de fato aconteceu um acordo ou um processo de gattopardismo, tendo em vista que o mesmo agradou para mais os que defendiam o investimento do dinheiro público nos estabelecimentos privados:

O pacto estabelecido satisfez bastante os agentes que defendiam o financiamento público dos estabelecimentos privados, a legitimidade da pré-seleção de alunos, a participação das famílias no financiamento das escolas particulares subvencionadas e a legitimidade do lucro dos proprietários desses estabelecimentos; ou seja, o consenso obtido entre

\footnotetext{
${ }^{6}$ Los padres tienen el derecho preferente y el deber de educar a sus hijos. Corresponderá al Estado otorgar especial protección al ejercicio de este derecho. Para el Estado es obligatorio promover la educación parvularia y garantizar el acceso gratuito y el financiamiento fiscal al segundo nivel de transición, sin que éste constituya requisito para el ingreso a la educación básica. La educación básica y la educación media son obligatorias, debiendo el Estado financiar un sistema gratuito con tal objeto, destinado a asegurar el acceso a ellas de toda la población. En el caso de la educación media este sistema, en conformidad a la ley, se extenderá hasta cumplir los 21 años de edad (CHILE, 2010).
} 
governo e oposição atendeu melhor aos interlocutores e analistas situados mais à direita do espectro político chileno (ZIBAS, 2008, p.207).

Na reflexão e análise da questão norteadora deste trabalho de pesquisa, que foi investigar quais foram as bases que fundamentaram os movimentos estudantis e, qual a sua contribuição para que o Chile se tornasse um país de referência na reforma do Ensino Médio, na América Latina, foi necessário compreender a contribuição de Allende como líder político. Segundo Florestan Fernandes (2018) é preciso reconhecer que a Via Chilena não era má em si mesma. O que ela foi é prematura. Ela exigia um avanço e um peso maiores dos regimes socialistas no equilíbrio mundial do poder.

No embate educacional chileno Salvador Allende (foto 01) deixou marcas que ainda sobrevivem. A Revolução dos Pinguins em 2006 movimentou o cenário educacional e impulsionou várias mudanças. Mas, o sistema educacional chileno vem tentando equilibrar políticas de mercado e regulação estatal. Foram realizadas algumas reformas e conseguiram diminuir os índices de pobreza e extrema pobreza, mas as desigualdades permaneceram e a luta entre público e privado na educação continua, apesar do país ser apontado como referência educacional na América Latina pela UNESCO.

Figura 3 - Manifestantes chilenos em 2013

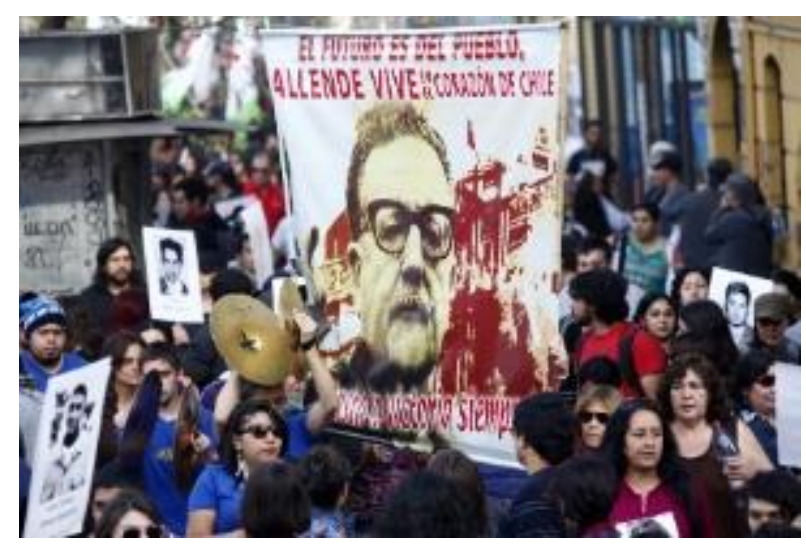

Fonte: Brodsky, 2013, on-line.

Cinco anos depois da Revolta dos Pinguins os estudantes saíram novamente às ruas, fortalecidos pela presença dos universitários, que também reivindicavam a gratuidade no ensino superior. Os protestos dinamizaram algumas reformas entre $2006 \mathrm{e}$ 2010, e entre 2014 e 2018. Mas, apesar das reformas educacionais chilenas serem 
consideradas vitrine para a América Latina, o ideal de uma escola democrática, inclusiva e não reprodutiva ainda é motivo de luta no Chile e a batalha entre o público e privado continua fomentada pelo neoliberalismo.

\section{CONCLUSÃO}

Neste artigo, pode-se refletir que durante o período de governo de Salvador Allende, nas políticas educacionais, a Unidade Popular, teve como preocupação manter uma lógica de ampliação do acesso à educação nos níveis primário, secundário e universitário, resultando na ampliação das infraestruturas, ou seja, na criação de novas escolas. A educação nesse período era pública e gratuita.

Em 1973, com o golpe de Estado, encerrou-se os processos de transformações sociais. Em um período de governo militar, aconteceu a intervenção nas universidades, toda política pública na educação foi por meio de decretos com força de lei, sem discussões, estabelecidas pela Junta Militar. Os conteúdos que mencionaram qualquer tipo de conceito como socialismo, luta de classes, movimentos sociais, democratização da cultura foram retirados do sistema educacional. Os militares ocuparam os cargos de reitores das Universidades e diretores de escolas públicas, ficando a educação sob o domínio das forças armadas. Com o governo militar, a educação básica e média do Chile se municipalizou, o estado deixou de assumir as Escolas públicas, ocasionando na segregação e desigualdades sociais.

As reformas que foram acontecendo no Chile causaram desagrados por parte de vários segmentos da sociedade, inclusive dos estudantes que saíram em passeatas pelas ruas de praticamente todas as regiões do Chile. Nesse sentido, percebeu-se que a educação no período em que Salvador Allende governou, foi considerado como um período em que a educação era acessível a toda a população, pois seu governo tinha como projeto a construção de várias escolas e projetos voltados a formação do novo homem chileno, como ampliar o acesso a opiniões mais amplas, não somente o da reprodução de ideias impostas por outros países, algo voltado totalmente para a realidade do povo chileno.

Dentre esses projetos, o da editora estatal, que divulgaria por meio de jornais e revistas as mensagens que contribuíram para a formação de pessoas críticas, conscientes da realidade dos chilenos. A revista Cabrochico foi um dos lançamentos da editora, destinada às crianças em fase pré-escolar e adolescentes que demonstravam os clássicos 
da literatura infantil de uma forma "diferente", levando os leitores a refletirem os comportamentos dos personagens principais não somente com a imagem de bonzinhos, simpáticos, corretos, honestos, mas que permitisse enxergar que por trás desses comportamentos existem outras intenções, que nem sempre são as mais justas, para o bem comum, com o "olhar" menos "romântico", com menos heróis das histórias que são difundidas nos países afora. Essa concepção de ideias nos faz refletir o que mudou nos comportamentos das gerações posteriores, os que foram leitores dessa revista, que podem ter deixado marcas profundas na juventude chilena.

A Revolta dos Pinguins, foi um marco de protestos não somente no Chile, mas na América Latina, tornando-se uma referência quando se trata desse tema, pois conseguiu se organizar e mobilizar praticamente todas as instituições escolares do Chile, contando com o apoio de vários segmentos da sociedade, universitários, sindicatos, diversos profissionais da saúde, operários e até de algumas escolas particulares. Dentre os resultados alcançados por esse movimento está a inscrição gratuita no Programa de Seleção Universitária, construção de um Cartão Nacional Estudantil e o passe escolar para os dias da semana completa.

Os impactos dos movimentos estudantis sobre as transformações na educação, em especial no ensino médio, que de acordo com as agências internacionais, é um modelo a ser seguido na América Latina, demonstra que essa nova organização estudantil trouxe uma herança na luta política chilena, um espaço de mudança de consciência. Embora o Chile seja considerado como um exemplo a ser seguido no ensino médio, constatou-se que este como em muitos outros países da América Latina, continuam com vários problemas de financiamentos, estruturas e qualidade do ensino. 


\section{REFERÊNCIAS}

AGGIO, Alberto. O Chile de Allende: entre a derrota e o fracasso. In: FICO, Carlos et al. (Org.). Ditadura e democracia na América Latina: balanço histórico e perspectivas. Rio de Janeiro: Fundação Getúlio Vargas, 2008. p. 77-93. in AGGIO, Alberto. Revolução e Democracia no nosso tempo. Franca: UNESP, 1997.

BORGES, E. ¡Con la UP ahora somos gobierno! A experiência dos Cordones Industriales no Chile de Allende. Rio de Janeiro, RJ. Tese de Doutorado. Universidade Federal Fluminense, 2011.

BLÁSQUEZ FIGUEROA, Amanda Gladyz. "La Fiesta y el Drama: Tomás Moulian e o Chile Contemporâneo (1970 - 2000). 2019. 181p. Dissertação de Mestrado. Universidade Estadual de Maringá - UEM. Maringá - Pr, 2019.

BRAGA, Leonardo Marmontel. Operação Condor: A internacionalização do terror. Estudios avanzados, n. 21, p. 111-136, 2014.

Brodsky, Roberto. 40 anos após golpe militar, Chile vive crise de maturidade. Uol Notícias. 2013. Disponível em: $<$ https://noticias.uol.com.br/ultimasnoticias/bbc/2013/09/11/chile-40-anos-apos-golpe-militar-pais-vive-crise-dematuridade.htm>. Acesso em: 15 de agosto de 2021.

BRUNNER, José Joaquín. Educación: y ahora, qué hacer? El Mercurio, p. D4, 12 dez. 2006.

CABALÍN, C. Neoliberal Education and Student Movements in Chile: inequities and malaise. Policy Futures in Education. v. 10, n. 2, 2012.

CABROCHICO, Santiago: Editora Nacional Quimantú, 1971-1972. 1v., año 1, nº 1, (jul. 1971).

CHILE, Biblioteca Nacional de. Memoriachilena. Disponível em: http://www.memoriachilena.gob.cl/602/w3-article-76538.html>. Acesso em: 30 jul. 2021.

CHILE, Mineduc. Informe sobre Escuela Nacional Unificada (ENU). Revista de Educación, Santiago do Chile: MINEDUC, Suplemento Especial, p. 69-88, feb. 973, 1973.

CHILE, Constitución Política De La República. Santiago de Chile: Jurídica de Chile, 2010.

CHILE, Ley $n^{\circ}$ 18.962, Ley Orgánica Constitucional de Enseñanza -Loce. Diario Oficial de 10 de marzo de 1990. Constitución Política de la República de Chile. Santiago de Chile: Jurídica de Chile, 2002. p. 611-647.

DALLO, Luana. PALUDO, Karina Inês. Adolescência: Perspectiva de Desconstrução de uma Visão Naturalizada. Schème: Revista eletrônica de Psicologia e epistemologia genética. UNESP, v4 n², ago-dez/2012. 
GOMES, Ivan Lima. A revista em quadrinhos Cabrochico e os debates culturais para a construção da "Via chilena para o socialismo" (1971 - 1972). História Unisinos. 16(1):43-54 Janeiro/Abril, 2012.

Para ler a Unidade Popular: Editora Quimantú e leituras para crianças durante 'A vila chilena para o socialismo' (1970-1973). Revista Brasileira para a educação (v. 21, 2021).

GOBIERNO DE CHILE, ALIANZA Y CONCERTACIÓN. Acuerdo por la Calidad de la Educación: documento técnico. Santiago, nov. 2007. Disponível em: <www.opech.cl>. Acesso em: fev. 2021.

HIGUERAS, Jorge Luis Inzunza. O neoliberalismo nas políticas educativas do Chile: da imposição ao consenso. FACSO Universidade do Chile, 2014.

HOBSBAWM, Eric J. Era dos Extremos: O breve século XX: 1914-1991. 2 ed. São Paulo: Companhia das Letras, 1995

KRAWCZYK, N. L. Prefacio. In: ADRIÃO, T.; GIL, J. (org.). Educação no Chile: olhares do Brasil. São Paulo: Xamã, 2009. p. 11-14.

LEAL, Leovegildo Pereira. Marxismo e Socialismo-Análise crítica da Revolução Cubana. Belo Horizonte: Fórum, 2008.

LIRA, Francisco R. F. T. de. Do socialismo ao neoliberalismo: o Chile dos anos 1970. Revista Vitrine da Conjuntura. FAE Centro Universitário. Curitiba, v.3, n.6, agosto 2010.

MENA, Victor. Distribución del ingreso en Chile: Una visión del ano 70 hasta hoy. Universidade Central do Chile, 2001. Disponível em: 〈http://www.ucentral.cl>. Acesso em: fev. 2021.

PEDROSO, Ledi Cerdote. ECONOMIC POLICY AND DISTRIBUTION OF INCOME: A COMPARATIVE ANALYSIS BETWEEN BRAZIL AND CHILE. 2007. 143 f. Dissertação (Mestrado em Direito) - Universidade Federal de Santa Maria, Santa Maria, 2007.

PEREIRA MELO, José Joaquim; ROSINA, Dhênis. Para o entendimento e a crítica do individualismo em Karl Marx. In: Encontro de Estudos em História, Trabalho e Educação, 2007, Campinas. Anais do Encontro de Estudos e Pesquisas em História, Trabalho e Educação. Campinas: UNICAMP, 2007. v. 1. p. 1-10.

Popular, U. (2021). Programa básico de gobierno de la Unidad Popular: candidatura presidencial de Salvador Allende. Anales de la Universidad de Chile, (18), pp. 372-420. doi:10.5354/0717-8883.2020.60836.

QUADRAT, Samantha Viz. A reforma educacional da Unidade popular e golpe no Chile (1973). Anais do XXVI Simpósio Nacional de História - ANPHU. São Paulo, Julho 2011. 
RUIZ-TAGLE, P. La trampa del neopresidencialismo: la Constitución "Gatopardo". In: CRISTI, R.; RUIZ-TAGLE, P. La república en Chile. Teoría y práctica del Constitucionalismo Republicano. Santiago: Lom Ediciones, 2006.

SANTOS, Emmanuel dos. Imprensa e poder político no Chile: o governo da Unidade Popular e os jornais El Mercurio e La Nación (1970-1973). 2018. 274 f. Dissertação (mestrado) - Universidade Federal de Minas Gerais, Faculdade de Filosofia e Ciências Humanas. Minas Gerais, 2018.

SILVA, A. S. Juventudes e movimentos de ocupação das escolas: caminhos e desafios para o ensino da geografia. 2017. $161 \mathrm{f}$. Dissertação de Mestrado - Universidade de Brasília, Brasília, 2017.

WINN, Peter. A revolução chilena. UNESP, 2010.

ZANATTA, Loris. Uma breve história da América Latina. Tradução Euclides Luiz Calloni. $1^{\mathrm{a}}$ ed. São Paulo: Cultrix, 2017.

ZIBAS, Dagmar M. L. A reforma do ensino médio no Chile: vitrina para a América Latina? Cadernos de Pesquisa, São Paulo: Fundação Carlos Chagas, n. 115, mar. 2002.

Recebido em: 20/10/2021

Aprovado em: 20/11/2021

Publicado em: 25/11/2021 